\title{
Quem cala consente? Ambientes digitais e suas implicações para a pesquisa antropológica
}

\author{
Helana MotTa Monaco (D) \\ Universidade Federal de Santa Catarina, Florianópolis, Santa Catarina, Brasil \\ helenamonaco@gmail.com
}

DOI 10.11606/issn.2316-9133.v29i2pe175295

\begin{abstract}
resumo Este artigo propõe reflexões éticas e metodológicas a respeito de pesquisas em ambientes digitais. Ele aborda duas situações etnográficas, vivenciadas em temporalidades distintas e junto a grupos diferentes numa mesma plataforma digital, o Facebook. Seu objetivo é explicitar os percursos traçados no trabalho de campo e as negociações com os sujeitos da pesquisa que, em um dos casos, impediu a realização da etnografia naquele ambiente. Comparando as duas situações, argumento que as diferenças encontradas na obtenção do consentimento para a realização da pesquisa dizem respeito às diferenças nos usos e sentidos atribuídos pelos sujeitos aos ambientes digitais que eles ocupam.
\end{abstract}

palavras-chave Antropologia digital. Ética. Consentimento. Gênero. Sexualidade.

Does silence give consent? Digital environments and their implications for anthropological research

abstract This article proposes ethical and methodological deliberations about research in digital environments. It addresses two ethnographic situations, experienced at different times and with different groups on the same digital platform, namely Facebook. It aims to explain the paths traced in the fieldwork and the negotiations with the research subjects that, in one case, prevented the realization of the ethnography in that environment. Comparing the two situations, I argue that the differences found in obtaining consent to conduct the research concern the different uses and meanings attributed by the subjects to the digital environments they occupy.

keywords Digital anthropology. Ethics. Consent. Gender. Sexuality. 


\section{¿Quien calla otorga? Entornos digitales y sus implicaciones para la investigación antropológica}

resumen Este artículo propone reflexiones éticas y metodológicas sobre la investigación en entornos digitales. Aborda dos situaciones etnográficas, vividas en diferentes momentos y con diferentes grupos en una misma plataforma digital, el Facebook. Su objetivo es explicar los caminos trazados en el trabajo de campo y las negociaciones con los sujetos de investigación que, en un caso, impidieron la realización de la etnografía en ese entorno. Comparando las dos situaciones, sostengo que las diferencias encontradas en la obtención del consentimiento para realizar la investigación se refieren a las diferencias en los usos y significados atribuidos por los sujetos a los entornos digitales que ocupan.

palabras clave Antropología digital. Ética. Consentimiento. Género. Sexualidad.

\section{Apresentação}

No presente trabalho, revisito duas pesquisas que realizei em temporalidades diferentes em uma mesma plataforma digital - a saber, o Facebook. Seu objetivo é explicitar os percursos traçados no trabalho de campo e as especificidades encontradas em cada uma das situações. A partir disso, proponho pensar os usos do digital pelos diferentes sujeitos das pesquisas e suas implicações éticas e metodológicas para a pesquisa antropológica, sobretudo no que diz respeito ao consentimento. Nas duas experiências etnográficas procurei utilizar o digital como ferramenta e lócus de pesquisa, em particular nos chamados grupos da rede social Facebook. Em ambos os casos, a proposta de pesquisa era observar publicações no interior desses grupos como uma das fontes da pesquisa, em conjunto com métodos analógicos de pesquisa etnográfica.

Proponho, aqui, algumas reflexões a partir da comparação dessas duas experiências. Se, num primeiro momento ambas as pesquisas pareciam se localizar no mesmo ambiente a saber, "grupos do Facebook" - a aproximação com o campo mostrou que se tratava de ambientes distintos. No primeiro caso, o acesso ao campo foi muito fácil e simples; no segundo, não obtive o consentimento de alguns sujeitos para a realização da pesquisa naquele espaço, devido aos usos e sentidos atribuídos a ele.

A primeira experiência diz respeito a uma pesquisa sobre o fisiculturismo feminino realizada entre os anos 2015 e 2016. O fisiculturismo é um esporte exclusivamente estético, que visa a adequação das formas corporais a padrões de competição e à apresentação da aparência dos corpos através de poses específicas, chamadas de "poses compulsórias", ou seja, formas minuciosas de posicionamento do corpo para realçar a musculatura. O esporte é 
pautado na potencialização muscular em volume, definição, proporção e simetria (JAEGER 2009). Há diferentes categorias de competição, que possuem critérios de avaliação distintos. As atletas do fisiculturismo moldam seus corpos através de exercícios físicos, dietas rígidas, e, por vezes, anabolizantes. Por ser muito relacionado à força física, o fisiculturismo se apresenta como um espaço de resistência para as mulheres que o praticam, que precisam lidar com a desvalorização simbólica das modalidades femininas do esporte, carência de patrocínios e menor premiação em dinheiro do que as categorias masculinas.

Para apreender as práticas culturais e sentidos atribuídos ao fisiculturismo praticado por mulheres, utilizei a abordagem etnográfica, através de entrevistas semiestruturadas com sete atletas do Fisiculturismo Feminino de categorias diferentes: Bikini Fitness, Wellness, BodyFitness Women's Physique ${ }^{1}$. Observei o treino técnico ${ }^{2}$ de duas atletas da categoria Wellness e um atleta da categoria Men's Physique, entrevistando também seu treinador. Além disso, realizei observação participante em dois eventos do esporte promovidos pela Federação Catarinense de Culturismo (IFBB-SC), sendo eles o Campeonato Estadual de Estreantes e o Campeonato Estadual, em Blumenau (SC) e em Camboriú (SC), respectivamente.

O foco principal dessa pesquisa foi nas diferenças de gênero observadas nos campeonatos, bem como nas falas das atletas a respeito das feminilidades de mulheres fisiculturistas. Para isso, observei também a interação das atletas e fãs ou aspirantes a atletas em ambientes digitais, principalmente grupos do Facebook, espaço onde ocorrem conversas e são compartilhadas fotos, vídeos, notícias, incluindo conversas informais e dicas de treino e dieta. Acompanhei, ainda, publicações de blogs relacionados ao esporte e vídeos de competições compartilhados no Youtube. Ademais, consultei os sites das confederações de fisiculturismo para compreender as diferenças entre as categorias de competição, tanto masculinas quanto femininas. Em especial, utilizei os sites da IFBB-Brasil (Confederação

\footnotetext{
${ }^{1}$ Há quatro categorias de fisiculturismo feminino no Brasil, Bikini fitness, Wrllness, Body fitness e Women's physique. Bikini Fitness: Caracterizada pelo baixo volume muscular e baixo percentual de gordura, onde a beleza facial, desenvoltura no palco, cabelo e maquiagem são avaliados. Wellness: Categoria criada no Brasil, caracterizada pela desproporção entre os membros superiores (menos hipertrofiados) e inferiores (mais volumosos). Apresenta baixo percentual de gordura e tônus muscular moderado, com ênfase no volume das pernas e glúteos. A desenvoltura no palco, sensualidade e beleza facial são avaliadas. BodyFitness: Apresenta volume muscular moderado, definição sem marcações, músculos firmes, baixo percentual de gordura e um corpo longilíneo em forma de "V". São avaliados cabelo, beleza facial e desenvoltura no palco. Women's Physique: Categoria com baixo percentual de gordura corporal, simetria e definição muscular. Os músculos devem apresentar uma forma arredondada e firme, com volume moderado. Ainda assim, é a categoria feminina que apresenta maior volume muscular. Também é considerada a desenvoltura e a personalidade na avaliação. 2 O "treino técnico" diz respeito ao aperfeiçoamento e ensaio das poses compulsórias para a competição, diferente do "treino" genérico, que diz respeito aos exercícios físicos propriamente ditos, para o desenvolvimento muscular e redução do percentual de gordura, a depender da fase de preparação da atleta.
} 
Brasileira de Musculação, Fisiculturismo e Fitness) e IFBB-SC, a fim de apreender a estrutura das competições e os critérios oficiais de julgamento das (os) atletas.

A segunda experiência etnográfica abordada neste artigo diz respeito a uma pesquisa sobre ativismo bissexual, realizada junto a um coletivo bissexual de São Paulo, em 2019, ao qual me refiro pelo pseudônimo "Coletivo B”. Uma característica importante desse coletivo é que sua atuação se dá em grande parte pela internet. Há, na literatura sobre bissexualidade, uma discussão sobre a existência ou não de espaços que podem ser caracterizados como bissexuais. Para Hemmings (2002), os espaços bissexuais são dificilmente encontrados ou identificados, apesar de a bissexualidade estar presente empiricamente em comunidades gays e lésbicas. Assim, em geral, os espaços bissexuais seriam comumente temporários e circunstanciais, materializados em conferências como a National Bisexual Conference, ou limitados alguns a grupos de apoio, não representando grandes comunidades reconhecíveis como as gays e lésbicas (HEMMINGS 2002). Emiel Maliepaard (2015), por sua vez, argumenta que tais espaços existem em práticas sociais e sexuais cotidianas.

No Brasil, espaços que poderiam ser identificados como bissexuais são ainda mais raros do que os casos descritos por Hemmings, por exemplo, nos Estados Unidos. Entretanto, tratar as plataformas digitais como ambientes, conforme sugerem Leitão e Gomes $(2011 ; 2017)$, permite percebê-las como espaços bissexuais. Isso porque alguns dos espaços de ativismo bissexual de maior abrangência, no Brasil, são aqueles organizados por coletivos em mídias digitais.

O coletivo B se autodeclara um coletivo de pessoas "monodissidentes", ou seja, pessoas com sexualidade e/ou afetividade dissidente da "monossexualidade", entendida como atração por apenas um gênero (como são os casos da heterossexualidade e da homossexualidade). Ele atua na cidade de São Paulo, mas principalmente na internet através de uma página pública no Facebook, um grupo fechado no mesmo site e um blog. O grupo do Facebook é composto não apenas por integrantes do coletivo, mas por alguns milhares de membros espalhados pelo Brasil. Nele, discutem-se aspectos da bissexualidade, experiências de vida, processos de aceitação, violências e preconceitos sofridos, além de desejos sexuais e afetivos. Ademais, os membros se organizam politicamente em torno da bissexualidade, criando mobilizações e ações de ativismo no meio digital, que extrapolam para outras plataformas e ferramentas de comunicação, como o aplicativo de mensagens WhatsApp, organização de eventos e atos presenciais.

A partir disso, tomei esse grupo como um espaço bissexual e me propus a fazer uma etnografia sobre ele. Entretanto, diferente do que ocorreu com a pesquisa sobre fisiculturismo, o processo de negociação da pesquisa, aqui, foi conturbado e levantou importantes questões éticas sobre consentimento e a pesquisa antropológica em meios digitais, como pretendo demonstrar nos próximos tópicos. Argumentarei que os diferentes 
sentidos atribuídos aos ambientes digitais impactaram a resposta dos interlocutores à minha entrada em campo como pesquisadora.

Tendo em vista a recusa dos interlocutores à participação na pesquisa, adotei métodos analógicos, como entrevistas com doze pessoas ligadas ao coletivo e observação participante em um evento presencial. Além disso, limitei a etnografia digital a ambientes onde minha entrada foi permitida - nomeadamente, aqueles identificados como públicos pela classificação do Facebook, administrados pelo coletivo. Não obstante, a recusa dos sujeitos da pesquisa não impediu que eu tivesse acesso a aspectos importantes dos usos do grupo por seus membros, que me foram apresentados não pela observação desse espaço, mas pelas entrevistas em profundidade com membros e participantes do coletivo.

Na próxima seção, examino em maiores detalhes os aspectos da pesquisa em mídias digitais realizada com fisiculturistas. $\mathrm{Na}$ seção seguinte, descrevo meus percursos de aproximação com o campo na pesquisa sobre ativismo bissexual, explicitando as dificuldades enfrentadas. Em seguida, teço algumas interpretações sobre as diferenças encontradas na aproximação com os dois grupos, bem como reflexões sobre as implicações éticas da pesquisa antropológica em mídias digitais, seus limites e possibilidades.

\section{Fisiculturismo, memes e o digital como ferramenta para circulação de conhecimento}

ideia de realizar uma pesquisa sobre fisiculturismo feminino surgiu a partir do meu uso das mídias digitais: foi a partir de um meme que vi no Facebook, compartilhado por um amigo, em 2014. Em contextos digitais, memes dizem respeito a ideias, brincadeiras, piadas ou comportamentos replicados de forma viral, usualmente pela repetição de um modelo básico do qual derivam novas versões do mesmo meme (FONTANELLA 2009). A perspectiva de Fontanella (2009) permite ter em vista a agência dos sujeitos que interagem e replicam o meme. Assim, a estrutura do meme estimularia a participação dos sujeitos e sua replicação através da criação de uma versão original, na medida em que é baseado em um modelo simples, sem exigir grandes conhecimentos técnicos para sua execução.

O meme em questão tinha uma estrutura comparativa, no estilo "expectativa versus realidade", mas com o diferencial de posicionar a "realidade" como preferível à "expectativa". Ele trazia duas fotos, de duas mulheres. À esquerda, uma fisiculturista, com estética semelhante à categoria de competição do fisiculturismo Women's Physique ou à categoria extinta Culturismo Feminino: musculatura volumosa, ombros largos, baixo percentual de gordura, com músculos marcados e veias aparentes. À direita, o meme trazia a imagem de uma mulher com a musculatura desenvolvida, porém menos volumosa, ombros e braços mais finos e um percentual de gordura mais alto - embora ainda magra - que tornava a musculatura menos definida. Acima da fotografia da esquerda, mais musculosa, havia a frase: 
"como as mulheres acham que ficariam se treinassem pesado". Acima da foto da mulher menos musculosa, havia a frase: "como elas realmente ficariam". Abaixo das fotos, o seguinte texto: "para com essa idiotice de 'eu prefiro celulite', levanta a bunda da cadeira e vai treinar".

O meme comparava a aparência física das duas mulheres: a mulher da direita, menos musculosa, teria uma aparência considerada desejável, que justificaria o "treino pesado", enquanto a mulher hipertrofiada da esquerda teria uma aparência considerada indesejável, que justificaria o medo desse treino. O "conselho" na parte inferior do meme retrataria um medo que as mulheres supostamente têm de construir medidas agigantadas e uma musculatura marcada, relacionada à atividade física identificada como "treino pesado" - ou seja, exercícios físicos que visam o desenvolvimento da musculatura, em geral por meio do levantamento de pesos.

Essa imagem despertou em mim uma curiosidade a respeito da mulher retratada na esquerda, considerada indesejável. Isso porque o desenvolvimento da musculatura para atingir os padrões das categorias mais volumosas de fisiculturismo requer grandes esforços, técnicas específicas, alimentação regrada e investimentos físicos, financeiros, sociais e emocionais. Nesse sentido, me perguntei: se as mulheres têm receio de "treinar pesado" por medo de desenvolver a musculatura, o que pensam as mulheres que se dedicam justamente a isso? O que leva uma mulher a querer desenvolver formas musculares agigantadas e definidas? Dito de outro modo, quem quer ser o lado esquerdo do meme?

Os corpos femininos hipertrofiados são considerados e retratados como abjetos (BUTLER 2016) por extrapolarem uma feminilidade normativa, uma vez que constroem corpos com medidas agigantadas, saindo do domínio de inteligibilidade que postula corpos femininos como pequenos e frágeis. Por isso, no contexto da pesquisa, importava quais eram as visões dessas mulheres sobre seus próprios corpos, subjetividades e as relações deles com aspectos de gênero e sexualidade.

No processo de aproximação com o campo, percebi que as chamadas redes sociais, e o Facebook mais especificamente, poderiam caracterizar um espaço importante para a realização da pesquisa, uma vez que o fisiculturismo é um esporte muito individual onde a preparação para as competições é feita no cotidiano da atleta. Essa preparação inclui a frequência em academias de ginástica, dietas e treinos das poses de palco. Mas não há uma academia específica para fisiculturistas onde todas se reúnem e onde eu poderia realizar um trabalho de campo prolongado. Percebi, entretanto, que havia alguns grupos e páginas de musculação e fisiculturismo no Facebook, e comecei a acompanhar esses ambientes de interação.

Entrei em diversos grupos de fisiculturismo no Facebook, que incluíam homens e mulheres entre seus membros e que, em geral, eram grupos abertos, de acordo com a classificação do próprio Facebook. Isso significa que qualquer pessoa poderia tornar-se 
membro do grupo, ver, comentar e fazer publicações em seu interior, sem precisar de autorização dos criadores ou moderadores do grupo. Ao entrar nesses grupos, fiz uma publicação me apresentando falando da pesquisa que pretendia fazer e seus objetivos. Questionei, ainda, se alguma mulher fisiculturista aceitaria conceder uma entrevista.

Em resposta à publicação, recebi algumas "curtidas" e uma pessoa entrou em contato para fazer entrevista. Eu entrevistei essa atleta e prossegui fazendo a observação dos grupos, considerando que, se não nenhuma pessoa havia questionado ou criticado a proposta, o grupo como um todo havia consentido à realização da pesquisa.

Os grupos não eram muito movimentados - o fluxo de publicações era relativamente baixo, ou seja, não havia publicações e comentários diários. Entretanto, de tempos em tempos, algum membro publicava uma dúvida, um meme, vídeos de campeonatos, fotos mostrando seus corpos (por vezes como evolução, do tipo "antes de depois") ou corpos de outros de atletas, além de serem comuns propagandas de suplementos, por exemplo. Outras pessoas interagiam com essas publicações e eu acompanhava tudo isso, tecendo diários de campo a partir das observações.

Apesar de o fluxo de publicações não ser tão intenso, o digital - e o Facebook particularmente - parecia ser um dos poucos lugares onde havia uma espécie de comunidade fisiculturista mais ampla e permanente, em contato próximo e cotidiano. Acredito, conforme mencionado, que isso se deve ao caráter individual do esporte, uma vez que as grandes reuniões de fisiculturistas acontecem poucas vezes ao ano, apenas nos campeonatos. Nesses grupos do Facebook, pude perceber algumas coisas que dificilmente acessaria em outros espaços, principalmente conflitos envolvendo críticas à aparência de mulheres musculosas. Ali, era possível observar as reações das atletas às ofensas recebidas, a partir dos comentários e de memes.

Isso aparecia fortemente nos memes compartilhados dentro dos grupos, que colocavam em evidência uma visão das atletas sobre as críticas que recebiam. Tais críticas eram entendidas como um indício de desejo reprimido por seus corpos. Assim, era comum que, em fotos de mulheres com musculosas compartilhadas nos grupos e páginas do Facebook, algumas pessoas fizessem comentários negativos, acusando as mulheres de serem feias, masculinas ou de "parecer homem".

Quando esse tipo de comentário negativo era feito por homens, os membros dos grupos respondiam que esses homens não gostam de mulheres musculosas porque são mais fracos do que elas - o que diminuiria sua masculinidade - ou, por outro lado, que na verdade eles sentem atração por elas, mas não admitem porque sabem que não conseguiriam nada com elas pois não despertariam seu interesse sexual ou afetivo - novamente, por serem fracos, ou "frangos". Por exemplo, em uma foto de uma mulher musculosa de biquíni, foi feito um comentário dizendo que ela era feia e tinha a aparência de um homem. Esse 
comentário recebeu respostas como: "Está com recalque porque ela é mais forte que você? [risos]" e "diz que é feia, mas se visse ela pessoalmente ficava de queixo no chão!!!". Isso mostra que as críticas e ofensas não são vistas como uma desaprovação real, mas como uma espécie de reação a um desejo que não pode ser satisfeito.

Nos casos em que as críticas são feitas por mulheres, isso era interpretado como inveja do corpo das atletas. Assim, entendia-se que uma mulher que as critica é feia e incapaz de alcançar os mesmos resultados. O comentário a seguir, de uma mulher, também extraído de um grupo do Facebook, ilustra essa situação: "Eu prefiro ficar 'masculina' e não ter aquelas pelancas que toda mulher tem. Acho deveriam exterminar pessoas invejosas da terra”.

Os memes compartilhados nesses espaços carregam e condensam queixas das atletas sobre preconceitos e discriminações sofridas com base em sua aparência. Mas além disso, demonstram uma resistência à associação entre músculo e masculinidade. Uma resposta frequente à acusação de que "músculo é coisa de homem" é justamente a seguinte: "então por que você não tem [músculos]?”. Esta resposta nega a associação de gênero dada à musculatura desenvolvida, mas, ao mesmo tempo, busca ofender e diminuir a masculinidade de quem as critica, invertendo sua própria lógica: se músculo é coisa de homem então quem critica mulheres musculosas é "menos homem" por ter pouco músculo, ou menos músculo do que uma mulher.

Uma das atletas que entrevistei indica que, em geral, a crítica a uma suposta masculinização de seus corpos provém de pessoas que não conhecem o esporte e não praticam o esporte e, por isso, seriam "frangos" ou "invejosas". Apesar disso, a preocupação de manter uma feminilidade normativa se faz presente também dentro do esporte. Nas regras de competição de cada categoria está sempre indicada a necessidade de manter a feminilidade da atleta, que também é lembrada pelos árbitros durante os campeonatos.

Esse discurso se faz presente também nas mídias digitais. Um exemplo disso é um texto de um blog sobre o esporte, chamado Agenda do Culturismo, que foi publicado em um grupo de fisiculturismo do Facebook. O texto, dedicado a mulheres, intitula-se "Esteroides e Virilização". Nele, o autor recomenda que as atletas tenham cuidado ao fazer uso de anabolizante devido ao "risco de virilização". Ele fala dos efeitos dos esteroides, dando muita ênfase ao fato de que eles, em suas palavras, "mutilam" os seios e que por isso mesmo a maioria das fisiculturistas faz uso do silicone, além do "risco" de engrossar a voz, aumentar o clitóris e fazer crescer pelos. Ele escreve: "Mulheres, o que os árbitros e público [das competições de fisiculturismo] querem ver no palco são mulheres, e não alguém com aparência de travesti, então ao usar esteroides androgênicos tenham muita cautela [...]”. E conclui: "Mesmo nas categorias como Bodybuilding feminino e Physique a feminilidade da atleta é avaliada, afinal de contas são mulheres, e devem se parecer o máximo possível com sua natureza” (grifos meus). 
Percebe-se, portanto, que os discursos sobre gênero e fisiculturismo nas mídias digitais não é homogêneo: de um lado, as atletas argumentam que as transformações corporais relacionadas ao esporte não diminuem sua feminilidade; de outro, são produzidos e compartilhados discursos como o descrito acima, que apelam para uma noção de natureza como fundamento para a associação entre características físicas e masculinidade.

Outro aspecto importante dos grupos de fisiculturismo no Facebook diz respeito à circulação de conhecimentos e técnicas de moldagem do corpo através de dietas e exercícios físicos, entendidos como dicas. Muitas vezes, essas publicações levavam a outras plataformas, como blogs relacionados a musculação e fisiculturismo que davam dicas detalhadas sobre o cotidiano do esporte, o funcionamento das dietas para ganho de massa muscular ou redução de gordura corporal e as diferentes fases de preparação para competições.

Assim, as fisiculturistas utilizavam o digital como uma ferramenta, não apenas para socialização, mas também para reunir informações sobre o esporte e circular dicas. Conforme mostrarei no próximo tópico, o grupo de ativismo bissexual fazia um uso muito distinto da plataforma, o que dificultou meu acesso ao grupo enquanto pesquisadora.

\section{Um espaço bissexual: antropóloga invasora}

Conforme mencionado, a segunda experiência etnográfica abordada neste artigo refere-se a uma pesquisa realizada em 2019 com ativistas integrantes de um coletivo bissexual. Uma das formas mais importantes de divulgar informações, reflexões e teorias a respeito da bissexualidade é o site do coletivo, onde são compartilhados diversos textos de autoria dos ativistas, além de documentos e textos estrangeiros traduzidos para o português. No período da pesquisa o site não foi atualizado, mas a partir de 2020 novos textos começaram a ser compartilhados com grande frequência.

Outro recurso do coletivo, este mais utilizado no período da pesquisa de campo, são as chamadas redes sociais: a página pública e especialmente grupo fechado do Facebook, onde há intensas discussões e trocas de informações e experiências entre membros. Ao contrário do que ocorria nos grupos sobre fisiculturismo, aqui o fluxo de publicações e comentários é intenso. Em um mesmo dia, podem ser acompanhadas diversas publicações diferentes, muitas vezes com longas conversas nos comentários. Outro aspecto diferente nesse grupo é que há uma série de regras, em um post fixado - ou seja, em uma publicação que fica sempre disponível na parte superior da tela quando se entra no grupo, sempre visível para os membros independentemente do fluxo de publicações. Nas regras do grupo - que estabelecem, inclusive, que elas precisam ser lidas por todos os membros ao entrarem consta que atitudes consideradas violentas ou preconceituosas serão motivo para banimento, mesmo que tenham ocorrido fora do grupo ou do Facebook. 
O grupo é "fechado", segundo a classificação do Facebook. Isso significa que os membros precisam de aprovação da moderação para poder acessar as publicações, comentar, curtir e publicar no grupo. Para solicitar a entrada e tornar-se membros, os solicitantes devem responder a três perguntas formuladas pela moderação. Em entrevista, Angelina ${ }^{3}$, uma das responsáveis pela avaliação das solicitações, explicou que só rejeita perfis que sejam obviamente falsos ou pessoas que estão "atrás de pegação". Aqui, os perfis falsos ou fake dizem respeito àqueles perfis em que não há convergência identitária, característica particularmente valorizada pelo Facebook (LEITÃO; GOMES 2017). Por sua vez, a "pegação" diz respeito a relações afetivo-sexuais efêmeras.

As perguntas a serem respondidas para entrada no grupo têm o objetivo de avaliar as intenções e o perfil do solicitante. A primeira delas é sobre atração sexual. São aceitas apenas membros que declaram sentir atração por mais de um gênero - ou seja, pessoas com práticas ou desejos bissexuais ${ }^{4}$ ou monodissidentes. Pode-se dizer que esta pergunta, portanto, se dedica a garantir a construção de uma "comunidade" bissexual que, tal como a ideia de identidade, é produzida a partir de exclusões e produções de diferenças (FACCHINI 2008).

Na segunda pergunta a ser respondida para entrar no grupo, o solicitante deve apenas confirmar que sabe que o grupo não é "catálogo de mulher pra ménage", ou seja, que não se trata de um grupo direcionado a encontros sexuais a três ou busca de parceiras bissexuais por parte de casais. De acordo com Angelina, essa pergunta existe porque a finalidade principal do grupo é ser uma comunidade, um espaço de troca de experiências. Assim, tentase evitar que o foco se volte para, em suas palavras, "pegação". Entretanto, os flertes são tolerados em alguma medida: há uma publicação, permitida pela moderação, chamada de "Tinder B", onde as pessoas colocam suas fotos e breves descrições, e utilizam o recurso "curtir" para demonstrar interesse umas nas outras.

A terceira e última pergunta é sobre alinhamento político. Nas regras do grupo, a moderação explica que não são aceitos membros que se identifiquem com ideologias que pregam discurso de ódio a determinados grupos. Angelina explicou que essa pergunta não tem a intenção de limitar o grupo apenas a um espectro político, mas de proteger os membros de possíveis ataques preconceituosos.

Mencionei anteriormente que a existência de espaços bissexuais é um ponto de discussão na literatura sobre bissexualidade. Por esse motivo, o grupo do coletivo B no

\footnotetext{
${ }^{3}$ Nome fictício, assim como todos os demais apresentados em referência aos interlocutores no texto.

${ }^{4}$ Utilizo a palavra "bissexual" aqui como termo guarda-chuva para designar pessoas que se atraem ou se relacionam sexual e/ou afetivamente com pessoas de mais de um gênero. Importa lembrar, entretanto, que há diferentes orientações e identidades políticas que designam esse tipo de desejo, a mais comum sendo a bissexualidade e a pansexualidade. O coletivo não limita a entrada de membros no grupo pelo termo "bissexual", mas utilizo o termo guarda-chuva aqui de modo a facilitar a leitura e compreensão.
} 
Facebook, que se propõe a ser uma comunidade para pessoas bissexuais, me interessou particularmente. De fato, o grupo conta com milhares de membros de todo o Brasil e se apresenta como um dos únicos espaços - talvez o único dessa amplitude - onde a bissexualidade é a temática central e o ponto de interesse comum.

Minha aproximação com o campo se deu primeiramente a partir da página oficial do coletivo no Facebook, por meio da qual entrei em contato com representantes, identificando-me como pesquisadora, explicitando os objetivos da pesquisa e questionando sobre a possibilidade de acompanhar suas atividades para os fins da pesquisa. Indaguei, ainda, sobre a possibilidade de realizar uma etnografia do grupo fechado organizado e mediado pelo coletivo. A representante com quem conversei entrou em contato com outros membros do coletivo, que permitiram que eu fizesse a etnografia também no grupo.

Entretanto, o grupo não é composto apenas por membros do coletivo. Conforme mencionado, ele é uma espécie de comunidade construída em torno da bissexualidade, que os membros utilizam primordialmente como forma de socialização e grupo de suporte emocional. Por isso, julguei necessário fazer uma publicação também no próprio grupo, apresentando-me como pesquisadora e explicitando os objetivos da pesquisa, para garantir o consentimento livre e esclarecido dos demais participantes do grupo, conforme o Código de Ética do Antropólogo e da Antropóloga (ABA 2012). Apesar do aceite do coletivo, entretanto, alguns integrantes do grupo, reagiram muito negativamente à proposta de pesquisa e recusaram a participação.

Não quero dar a entender, aqui, que recebi apenas reações negativas. De fato, minha publicação no grupo recebeu reações positivas - como curtidas, comentários positivos e elogiosos. Mas, poucos minutos depois da publicação, uma recebi também comentários de pessoas muito ofendidas com a proposta de pesquisa, me acusando de ser antiética por querer observar aquele espaço. Outras pessoas interviram para me defender - algumas, inclusive, alegando que elas mesmas já faziam pesquisa no grupo e que eu estaria apenas tentando oficializar algo que já ocorre informalmente.

Respondi os comentários negativos, buscando esclarecer desentendimentos, já que a maioria parecia pensar que eu já estava realizando a pesquisa, sem ter me apresentado antes. Procurei, portanto, demonstrar que eu estava justamente pedindo o consentimento dos membros do grupo e a construção conjunta. Argumentei que não faria a pesquisa no grupo caso não fosse de seu interesse. Assim, pude estabelecer um diálogo mais próximo com aqueles que se sentiram ofendidos, ainda que de forma conflituosa. Por dele, consegui convencer a maioria das pessoas que comentaram negativamente; estas passaram a dizer que não haveria problema na realização da pesquisa. Entretanto, algumas continuaram recusando a proposta ou simplesmente pararam de responder. 
O principal argumento justificando a recusa à pesquisa, para além dos desentendimentos que foram esclarecidos, dizia respeito à importância do grupo para seus membros. Assim, eles argumentaram que aquele grupo em particular era o único lugar onde podiam ser verdadeiros enquanto pessoas bissexuais. Era um lugar onde poderiam se abrir, falar de suas angústias, suas dúvidas, suas confusões, sem serem julgados ou sofrer preconceito. $\mathrm{O}$ único espaço bissexual ao qual tinham acesso estava restrito àquele ambiente digital, não existindo outros grupos, digitais ou analógicos, em que a bissexualidade pudesse ser vivenciada da mesma forma.

Por esse motivo, argumentavam que não queriam que o grupo fosse "vigiado" por uma pesquisadora, uma vez que isso os deixaria menos confortáveis para se abrir e expor suas dúvidas e angústias. Faria com que o grupo não pudesse mais ser um espaço seguro para pessoas bissexuais interagirem umas com as outras. É nesse sentido que fui compreendida como uma invasora daquele espaço, como alguém que, a partir de seu olhar, colocaria em risco a comunidade bissexual ali construída.

Depois do ocorrido, conversei novamente com uma representante do coletivo, que me disse que ficou surpresa e "horrorizada" com a reação das pessoas no grupo, e questionou se eu não poderia fazer a pesquisa mesmo assim, ignorando os protestos. Apesar dessa sugestão, decidi mudar a proposta da pesquisa, não fazer a observação do grupo e voltar minha atenção às publicações da página do coletivo. Fiz isso por considerar importante respeitar a vontade dos membros do grupo, ao invés de impor a minha presença e minha pesquisa. Assim, limitei minhas observações nos ambientes digitais aos canais oficiais e públicos do coletivo, isto é, às publicações da página pública administrada por ele, e não às publicações dos membros no grupo.

Entretanto, mesmo sem fazer a observação participante diretamente no grupo, ele acabou por se mostrar importante na minha pesquisa, justamente por ser valorizado pelos sujeitos. Percebi que não se tratava de um espaço à parte em suas vidas, mas de um ambiente central na experiência da bissexualidade, como um espaço coletivo de construção de subjetividades bissexuais.

A coletividade bissexual presente nesse espaço é vista pelos interlocutores como essencial para seu processo de identificação como bissexuais e para combater o sofrimento causado pela bifobia (DOMÍNGUEZ RUIZ 2017). É a partir do contato com outras pessoas bissexuais, frequentemente no grupo do Facebook, que os a bissexualidade entra em um regime de inteligibilidade (BUTLER 2016), permitindo a identificação. Nesse sentido, pude acessar o grupo não pela observação direta, mas pelos relatos trazidos nas entrevistas semiestruturadas que realizei posteriormente, com ativistas e participantes do coletivo.

Para além da importância do coletivo para as entrevistadas, ele e outros ambientes digitais foram essenciais para a formulação do meu projeto e questões de pesquisa. 
Acompanhando esse grupo e algumas outras páginas sobre bissexualidade no Facebook, que eram mais ativas entre 2017 e 2018, quando eu estava formulando o projeto de pesquisa, identifiquei algumas questões que eram importantes no ativismo bissexual, e que eu teria que abordar no meu trabalho. Uma delas, para citar apenas um exemplo, é a questão da saúde mental, uma vez que as ativistas bissexuais argumentam que pessoas bissexuais teriam maior incidência de problemas relacionados a saúde mental, porque sofrem preconceito e rejeição tanto de heterossexuais quanto de gays e lésbicas. Foi a partir desses ambientes digitais que eu pude identificar que esta seria uma questão relevante para levar a campo. Apesar de não ter feito parte da pesquisa de campo propriamente dita, esse espaço bissexual foi essencial para formular as perguntas de pesquisa e me preparar para as entrevistas com ativistas. Sem a aproximação prévia desse espaço eu não teria conhecimento da dimensão que questões de saúde mental têm para os sujeitos da pesquisa.

Até o momento, procurei descrever duas experiências de pesquisa etnográfica em ambientes digitais. No próximo tópico, estabeleço algumas comparações entre elas e algumas hipóteses explicativas para a diferença drástica entre a reação à pesquisa por parte das fisiculturistas e de ativistas bissexuais ligados aos grupos.

\section{Quem pode consentir?}

A partir do exposto até aqui, é evidente que a aproximação com o campo, no caso do grupo de ativismo bissexual, foi muito conturbada se comparada à mesma situação nos grupos de fisiculturismo. É essa diferença entre reações - de um lado positivas ou desinteressadas e, de outro, negativas e até mesmo agressivas - que acho particularmente curiosa. Essa diferença tem origem nos diferentes usos e sentidos atribuídos às mídias digitais pelos dois grupos. Importa lembrar que a internet ou o digital não são homogêneos, mas, ao contrário, são inventados localmente pelos seus usuários (MILLER; HORST 2015).

As fisiculturistas, membras dos grupos de fisiculturismo no Facebook, foram indiferentes, ou seja, não manifestaram opiniões, ou então responderam positivamente, uma delas entrando em contato para entrevista em profundidade. Elas procuravam, nos espaços digitais, dicas de dieta e exercício, além de humor relacionado ao esporte. Mas, apesar de ser utilizado como um meio de defesa com relação a críticas à sua aparência, aquele espaço não era importante para que elas construíssem e defendessem uma identidade política; não era parte fundamental de seu cotidiano.

Por sua vez, as pessoas bissexuais do grupo do coletivo B estavam naquele espaço construindo uma comunidade que não existe em outros lugares de suas vidas. Nesse sentido, para os sujeitos bissexuais, o grupo era muito importante para o seu cotidiano e para afirmar uma identidade política. O grupo era visto não apenas como um ambiente de informação e descontração - como nos grupos de fisiculturismo - mas como um espaço de acolhimento 
em meio a preconceitos que vivenciados fora dele. É por esse motivo que, para algumas pessoas do grupo, ele não deveria ser invadido por uma pesquisadora ou colocado em risco por conta de uma pesquisa.

Mas, como mencionei, meu entendimento dos sentidos atribuídos ao grupo por parte dos sujeitos bissexuais não veio apenas do conflito que minha apresentação causou. Isso apareceu nas entrevistas que eu fiz com pessoas que fazem parte dele. Para algumas delas, o grupo permite viver a bissexualidade e compartilhá-la sem necessariamente ter que "sair do armário" em outros espaços, como na família ou no trabalho. Assim, o grupo garante uma espécie de anonimato que permite expor aspectos íntimos da vida através do compartilhamento com desconhecidos que, embora sejam desconhecidos, têm a bissexualidade como característica comum.

Ao iniciar a pesquisa sobre bissexualidade e pensar em fazer uma etnografia do grupo do Facebook, pensei que bastaria repetir os mesmos procedimentos já adotados na pesquisa sobre o fisiculturismo, uma vez que, em minha concepção, tratava-se da mesma plataforma - o Facebook - e a mesma ferramenta - o "grupo". Entretanto, o que esse conflito com os sujeitos mostrou é que são, de fato, espaços distintos, apesar de estarem atrelados à mesma plataforma. Nesse sentido, não é a plataforma Facebook que determina os usos e os sentidos atribuídos àquele espaço, ou a forma que esse espaço terá. Ao contrário, o próprio Facebook é criado e recriado pelos sujeitos, em seus usos cotidianos, suas práticas e relações sociais e as dinâmicas internas dos espaços vividos e imaginados nessa plataforma.

Para além disso, importa destacar que os sentidos atribuídos aos espaços, sejam eles digitais ou analógicos, não são homogêneos. Haverá divergências no interior de um mesmo grupo, como pude observar nas diferentes reações à proposta de pesquisa entre os membros do grupo bissexual: algumas pessoas se ofenderam, outras elogiaram. A maior disparidade é aquela entre os representantes do coletivo, criador e administrador do grupo, e esses membros que se sentiriam lesados com uma pesquisa naquele espaço. Enquanto o coletivo almejava a visibilidade de seus espaços, suas pautas e à bissexualidade no geral, esses membros desejavam um espaço em que pudessem manter um anonimato, em que possam falar livremente sobre suas bissexualidades, sem preocupação com o olhar externo.

Caberia questionar, portanto, se o consentimento das lideranças desses espaços - ou seja, dos moderadores do grupo, nesse caso, o coletivo B - seria suficiente para garantir o consentimento do grupo como um todo. Em outras palavras, quem tem o direito de consentir ou recusar a participação na pesquisa antropológica? E, ainda, a quem pertencem os espaços digitais - aos criadores (sejam eles as empresas como o Facebook ou os administradores de grupos e páginas) ou às pessoas que vivenciam e constroem cotidianamente aqueles espaços? 
Sabe-se que o percurso no campo não depende só do antropólogo ou antropóloga, por ser demarcado e delimitado por itinerários aceitos pelos interlocutores da pesquisa (SILVA 2009); entretanto, as definições desses limites não têm contornos rígidos e homogêneos, pois os próprios grupos estudados são diversos e repletos de disputas internas. Essas questões colocam a pesquisadora em uma posição ambígua, de decidir qual consentimento "vale" ou é suficiente, uma vez que me foi sugerido por uma liderança do coletivo que continuasse a proposta de pesquisa, mesmo sem o consentimento das pessoas que reagiram à minha publicação.

Não há resposta pronta e universal a essas questões, mas, no caso aqui abordado, a solução que adotada foi construir a pesquisa em conjunto com os sujeitos, aqueles que quiseram construir, dentro dos limites que as negociações permitiram. Daí a importância de negociar com os sujeitos da pesquisa, reconhecendo-os como entidades políticas dotadas de critérios de avaliação ética (FONSECA 2015). Importa lembrar que a relação entre pesquisadora e pesquisados na pesquisa etnográfica é desigual e assimétrica (SILVA 2000), uma vez que, como pesquisadora e sobretudo como autora, eu já terei a palavra final, no texto. Por isso, é imprescindível garantir que os sujeitos da pesquisa tenham algum dizer sobre a narrativa que será escrita sobre eles, afinal, são narrativas sobre suas vidas, e dar acesso a elas a uma pesquisadora é uma dádiva que, como tal, deve ser retribuída (MAUSS 2017) na forma de uma visibilidade positiva que respeite seus interesses, seus próprios termos e suas ponderações sobre aspectos éticos da pesquisa.

Marilyn Strathern (2017) a antropologia engloba e domestica os usos que outras pessoas fazem de suas vidas, o que, por vezes, pode ser vivenciado como uma exploração. Isso porque as pessoas pesquisadas percebem que esse englobamento significa uma transformação dos dados em materiais cujo valor não pode ser restituído a elas. Desse modo, nas palavras da autora, "considera-se [...] que os antropólogos convertem a experiência vivida em itens [...] cuja utilidade, como elementos para seus próprios modelos, somente eles controlam” (STRATHERN 2017: p.150).

Essas reflexões auxiliam na compreensão da resistência que encontrei por parte dos interlocutores da pesquisa, que não refletia a visão do coletivo e seus representantes. Para o coletivo, a visibilidade das pautas do movimento bissexual em uma pesquisa acadêmica parece ser retribuição suficiente para os dados concedidos à pesquisadora, tendo em vista que uma das principais pautas dos movimentos bissexuais brasileiros diz respeito à visibilidade. Para alguns integrantes do grupo do Facebook, entretanto, a visibilidade não é pauta prioritária e, ao contrário, poderia até mesmo ser prejudicial, uma vez que o anonimato no grupo oferece uma sensação de segurança para falar abertamente sobre sexualidade. 
Ademais, o conflito ocorrido nesse grupo me levou a questionar também as implicações éticas da pesquisa realizada com fisiculturistas, especialmente no que diz respeito ao consentimento. Assim, me pergunto se algumas curtidas, respostas positivas e a omissão da maioria das integrantes dos grupos seria suficiente para garantir o consentimento das pessoas ao observar os ambientes digitais. Em outras palavras, para citar a expressão popular que dá título a este artigo, quem cala consente?

O Código de Ética do Antropólogo e da Antropóloga (ABA 2012) prevê que as populações pesquisadas têm o direito de recusar a participação e de ser informadas sobre a natureza da pesquisa. Ora, em um grupo com milhares de pessoas seria impossível garantir que todas visualizaram, leram e compreenderam a natureza da pesquisa proposta e, ainda, que concedam expressamente seu consentimento.

Não obstante, importa lembrar, conforme Didier Fassin (2006), que o trabalho de campo não tem fronteiras definidas entre vida e pesquisa. Ele está por toda parte e a observação participante é caracterizada por sua informalidade. Nesse sentido, estamos sempre observando e a vida faz parte da pesquisa. Por sua vez, as mídias digitais são parte importante da vida cotidiana de grande parte das pessoas, inclusive pesquisadoras. Como antropóloga, não há como separar estritamente o que eu vejo, ouço e faço nos ambientes digitais por onde circulo e os dados de pesquisa construídos na relação com os sujeitos. Meu olhar sobre esses dados será permeado por minhas próprias experiências digitais e analógicas. Por isso, a perspectiva parcial se mostra tão importante na construção de um conhecimento que não se pretende universal, mas situado (HARAWAY 1995).

\section{Considerações finais}

Ao longo deste artigo, procurei levantar algumas questões suscitadas por duas pesquisas realizadas em ambientes digitais, mais especificamente em grupos do Facebook. $\mathrm{O}$ primeiro caso diz respeito a uma pesquisa sobre fisiculturismo feminino, onde a entrada em campo se deu de forma simples e sem conflitos. O segundo diz respeito a uma pesquisa sobre ativismo bissexual, onde houve uma recusa, por parte dos integrantes do grupo, à participação na pesquisa, embora o coletivo responsável pela administração do grupo tenha consentido previamente.

Em ambos os casos, a pesquisa não se restringiu às mídias digitais, contando com métodos analógicos, como a observação participante em campeonatos, no caso do fisiculturismo, e em um evento promovido pelo coletivo, no caso da pesquisa sobre ativismo bissexual. Ambas contaram, ainda, com entrevistas semiestruturadas. Algumas atletas fisiculturistas relataram que foi justamente por ambientes digitais que que elas conheceram e se interessaram pelo esporte. Já para os sujeitos bissexuais, a aproximação com tais ambientes apareceu mais fortemente como elemento chave para a construção de uma 
subjetividade bissexual, de modo que fica evidente a importância desses espaços em suas construções do "eu" bissexual.

De minha parte, foi através das mídias digitais que consegui me familiarizar com grande parte das categorias êmicas utilizadas tanto pelas atletas quanto pelos ativistas, podendo compreender, de um lado, a rotina do esporte e, de outro, as demandas políticas relacionadas à bissexualidade. Vale lembrar que o trabalho etnográfico envolve um processo de descrição e tradução, senão de uma língua para outra, ao menos dos sentidos de práticas e termos êmicos. Mesmo em pesquisas realizadas dentro da cultura ou do idioma da pesquisadora, certa tradução se faz necessária para dar conta das relações e significados específicos ao contexto de determinado grupo pesquisado, mas em diálogo com o contexto das discussões acadêmicas. Assim, colocam-se desafios de traduzir e descrever tanto expressões quanto relações, sem subordiná-las às nossas categorias (BARBOSA 2007: 153). A aproximação aos ambientes digitais mostrou-se como uma estratégia valorosa na compreensão dessas categorias e relações, que foram úteis não apenas no momento da pesquisa, mas também na construção de um projeto de pesquisa que visava dar conta das demandas e temas de interesse dos sujeitos estudados.

Procurei demonstrar, a partir da apresentação dessas duas experiências de pesquisa, que as diferenças no acesso ao campo tiveram origem em uma diferença fundamental na visão dos sujeitos sobre aqueles espaços digitais. No caso das fisiculturistas, o espaço dos grupos do Facebook era utilizado para procurar dicas relacionadas ao esporte e para compartilhar memes. Por sua vez, os sujeitos bissexuais procuravam no grupo do coletivo B a construção de uma comunidade bissexual que não existe em outros espaços. Isso fez com que recusassem a realização da pesquisa por considerar que minha presença como pesquisadora colocaria esse espaço em risco. Para os bissexuais, o grupo era um espaço relevante para o cotidiano e para sua afirmação identitária: o viam como um espaço de acolhimento em meio a uma chuva de bifobia (DOMÍNGUEZ RUIZ 2017), e por isso esse espaço não deveria ser incomodado por conta de uma pesquisa.

Essas situações fornecem algumas pistas sobre como lidar com os conflitos e problemáticas que podem ser encontradas ao realizar pesquisas em ambientes digitais. É preciso ter em vista a forma como a presença da pesquisadora nesses espaços pode afetar e alterar os próprios espaços, ou a percepção dos espaços por parte dos membros, uma vez que, ao observarmos ambientes digitais, também somos observadas (LEITÃO; GOMES 2017). Se minha presença naquele espaço foi vista como uma ameaça para o grupo e seus integrantes, vale questionar quais seriam as implicações éticas de considerar o consentimento das lideranças do grupo como suficiente para a realização da pesquisa. Dito de outro modo, é necessário levar a sério o direito dos grupos estudados de se recusar a participar de uma pesquisa antropológica. Por isso, pesquisas em ambientes digitais, em 
especial aqueles com grande fluxo de pessoas, colocam importantes desafios sobre ética e consentimento na pesquisa antropológica.

Não parece possível garanti o consentimento livre e esclarecido de todos os participantes em um grupo de milhares de pessoas, onde o fluxo de publicações e interações tão é alto que qualquer uma delas pode desaparecer do centro de discussões em poucas horas. Mesmo sem conflitos, como no caso dos grupos de fisiculturismo, não há como garantir que uma publicação da pesquisadora será lida - e compreendida -todos os integrantes do grupo. Em outras palavras, calar-se nem sempre significa consentir.

\section{Referências bibliográficas}

ABA - Associação Brasileira de Antropologia. (2012). Código de Ética do Antropólogo e da Antropóloga. Brasília, ABA. Disponível em: http://www.portal.abant.org.br/codigo-deetica/. Acesso em 30 set 2020.

BARBOSA, Gabriel Coutinho. (2007). Os Aparai e Wayana e suas redes de intercâmbio. Tese de Doutorado. São Paulo: PPGAS/USP.

BUTLER, Judith. (2016). Problemas de gênero: Feminismo e subversão da identidade. Tradução de Renato Aquiar. Rio de Janeiro: Civilização Brasileira.

DOMÍNGUEZ RUIZ, Ignacio Elpidio. (2017). Bifobia: Etnografía de la bisexualidad en el activismo LGTB. Barcelona/Madrid: Editorial Egales.

FACCHINI, Regina. (2008). Entre umas e outras: mulheres, (homo)sexualidades e diferenças na cidade de São Paulo. Tese de Doutorado. Campinas: PPGCS/Unicamp.

FASSIN, Didier. (2006). The end of ethnography as collateral damage of ethical regulation? In: American Ethnologist, vol. 33, n. 4, p. 522-524.

FONSECA, Claudia. (2015). Situando os comitês de ética em pesquisa: o sistema CEP (Brasil) em perspectiva. In: Horizontes Antropológicos, ano 21, n.44, p. 333-369.

FONTANELLA, Fernando. (2009). O que é um meme na Internet? Proposta para uma problemática da memesfera. Trabalho apresentado no III Simpósio Nacional da ABCiber.

HARAWAY, Donna. (1995). Saberes localizados: a questão da ciência para o feminismo e o privilégio da perspectiva parcial. In: Cadernos Pagu, n.5, p. 7-41.

HEMMINGS, Clare. (2002). Bisexual spaces: A geography of sexuality and gender. New York: Routledge.

JAEGER, Angelita Alice. (2009). Mulheres atletas da potencialização muscular e a construção de arquiteturas corporais no fisiculturismo. Tese de Doutorado. Porto Alegre: PPG-Ciências do Movimento/UFRGS.

LEITÃO, Débora; GOMES, Laura Graziela. (2017). Etnografia em ambientes digitais: perambulações, acompanhamentos e imersões. In: Antropolítica, n. 42, p. 41-65 
LEITÃO, Débora; GOMES, Laura Graziela. (2011). Estar e não estar lá, eis a questão: pesquisa etnográfica no Second Life. In: Revista Cronos, v. 12, n. 1, p. 25-40.

MALIEPAARD, Emiel. (2015). Bisexuals in space and geography: More-than-queer? In: Fennia, vol.193, n.1, p. 148-159.

MAUSS, Marcel. (2017). "Ensaio sobre a dádiva”. In: MAUSS, Marcel. Sociologia e antropologia. Tradução de Paulo Neves. São Paulo: Ubu Editora.

MILLER, Daniel; HORST, Heather. (2015). O Digital e o Humano: prospecto para uma Antropologia Digital. In: Parágrafo, v. 2, n. 3, p. 91-111.

SILVA, Hélio. (2009). A Situação Etnográfica: andar e ver. In: Horizontes Antropológicos, ano 15, n.32, p. 171-188.

SILVA, Vagner Gonçalves da. (2000). O Antropólogo e sua Magia: Trabalho de campo e texto etnográfico nas pesquisas antropológicas sobre religiões afro-brasileiras. São Paulo: Editora da Universidade de São Paulo.

STRATHERN, Marilyn. (2017). Os limites da autoantropologia. In: STRATHERN, Marilyn. O efeito etnográfico e outros ensaios. Tradução do capítulo por Iracema Dulley. São Paulo: Ubu Editora.

sobre a autora

\section{Helena Motta Monaco}

Mestra em Antropologia Social (2020) pelo Programa de PósGraduação em Antropologia Social (PPGAS) da Universidade Federal de Santa Catarina. Possui bacharelado (2017) e licenciatura (2018) em Ciências Sociais pela Universidade Federal de Santa Catarina (UFSC).

Recebido em 30/09/2020 Aceito para publicação em 04/12/2020 